\title{
Efficient desulfurization of gasoline fuel using ionic liquid extraction as a complementary process to adsorptive desulfurization
}

\author{
N. Farzin Nejad ${ }^{1}$ A. A. Miran Beigi ${ }^{1}$
}

Received: 18 July 2014/ Published online: 28 March 2015

(c) The Author(s) 2015. This article is published with open access at Springerlink.com

\begin{abstract}
The extractive desulfurization of a model gasoline containing several alkyl thiols and aromatic thiophenic compounds was investigated using two imidazolium-based ionic liquids (ILs), 1-butyl-3-methylimidazolium tetrachloroaluminate, and 1-octyl-3-methylimidazolium tetrafluoroborate, as extractants. A fractional factorial design of experiments was employed to evaluate the effects and possible interactions of several process variables. Analysis of variance tests indicated that the number of extraction steps and the IL/gasoline volume ratio were of statistically highly significant, but none of the interactions were significant. The results showed that the desulfurization efficiency of the model gasoline by the ILs could reach $95.2 \%$ under the optimal conditions. The optimized conditions were applied to study the extraction of thiophenic compounds in model gasoline and several real gasoline samples; the following order was observed in their separation: benzothiophene $>$ thiophene $>3$-methylthiophene $>2$-methylthiophene, with $96.1 \%$ removal efficiency for benzothiophene. The IL extraction was successfully applied as a complementary process to the adsorptive desulfurization with activated Raney nickel and acetonitrile solvent. The results indicated that the adsorptive process combined with IL extraction could provide high efficiency and selectivity, which can be regarded as a promising energy efficient desulfurization strategy for production of low-sulfur gasoline.
\end{abstract}

\footnotetext{
N. Farzin Nejad

Farzinnejadn@ ripi.ir

1 Petroleum Refining Technology Development Division, Research Institute of Petroleum Industry, 14857-33111 Tehran, Iran
}

Edited by Xiu-Qin Zhu
Keywords Liquid-liquid extraction · Experimental design · Adsorptive desulfurization · Gasoline · Thiophenic compounds

\section{Introduction}

Sulfur oxides $\left(\mathrm{SO}_{x}\right)$ resulting from the combustion of sulfur compounds in fuels have become an increasingly serious environmental problem worldwide as they are a major cause of acid rain and atmospheric pollution. Thus, in recent years, considerable attention has been paid to the deep desulfurization of gasoline and diesel fuels due to the increasingly stringent environmental regulations being imposed to reduce the $\mathrm{S}$ content to a very low level (Song 2003).

The removal of sulfur compounds from liquid fuels is carried out industrially via catalytic hydrodesulfurization (HDS). Although the conventional HDS has been highly effective in reduction of sulfur levels, aromatic sulfur compounds such as thiophene, benzothiophene, dibenzothiophene, and their derivatives, which are the major objectionable sulfur components present in petroleum fractions, are less reactive to this process (Song 2003). Further improvement of the HDS process for deep desulfurization is limited to increasingly severe operating conditions at high cost. Moreover, deep HDS process will require a considerable increase in the consumption of energy and hydrogen, which can substantially improve the reactivity and selectivity of the catalyst, resulting in undesirable side reactions. Such side reactions can lead to a decrease in the octane number of gasoline (Nie et al. 2006; Wang et al. 2007). Therefore, from both environmental and economic considerations, various alternative deep desulfurization processes have been extensively developed in 
the past few years, including adsorptive and complexation desulfurization (Mansouri et al. 2014; Sevignon et al. 2005; Shi et al. 2015), biodesulfurization (Boshagh et al. 2014; Fernandez et al. 2014), extractive desulfurization (Mokhtar et al. 2014; Domanska et al. 2014; Krolikowski et al. 2013), and oxidative desulfurization (ODS) followed by extraction (Zhang et al. 2013; Ma et al. 2014).

Among the above alternatives, extractive desulfurization deserves special attention because the extraction is a wellestablished and facile process that can be carried out at or around ambient temperature and pressure. However, a suitable solvent for extractive desulfurization should have a high partition coefficient for sulfur components especially aromatic sulfur compounds, negligible cross solubility, high thermal and chemical stability, nontoxicity, environmental compatibility, and low cost for commercial applications (Jiang et al. 2008). Many organic solvents, such as dimethyl sulfoxide, acetonitrile, 1-methyl-2-pyrrolidinone, dimethylformamide, and polyalkylene glycol have been used as extractants, but none of these solvents conform to all of the above requirements and their performance in removing sulfur from fuels has not been satisfactory ( $\mathrm{Li}$ et al. 2010; Sampanthar et al. 2006).

The ionic liquids (ILs) have been recognized as promising alternatives to conventional non-desirable organic solvents and have received considerable attention as extractants for desulfurization of liquid fuels ( $\mathrm{Li}$ et al. 2010; Mochizuki and Sugawara 2008; Kedra-Krolik et al. 2011; Hansmeier et al. 2011), or at least as a complementary technology to the HDS process (Nie et al. 2008). The ILs are environmentally friendly solvents with unique physicochemical properties, such as negligible vapor pressure, high chemical and thermal stabilities, nonflammability, and recyclability. These properties together with high affinity for sulfur-containing compounds, especially aromatic sulfur components, and immiscibility with fuels make ILs desirable extractants for desulfurization of liquid fuels (Wang et al. 2007; Kedra-Krolik et al. 2011). However, although ILs are highly effective for the extraction of some aromatic sulfur components, that is, they can lower the concentrations to desirable low levels (especially thiophenic compounds), they do not provide adequate efficiency for decreasing the total sulfur concentration to acceptable levels for many gasoline samples. Activated Raney nickel adsorbent combined with IL extraction is regarded as a promising strategy to achieve very low sulfur levels and is currently receiving increasing attention because it avoids the use of hydrogen and allows the process to be conducted at ambient conditions. This process is also appealing because the sulfur contaminants that are most resistant to HDS, such as thiophenic compounds, are the most reactive components under ambient conditions.
A survey of the literature shows that many factors, such as the type of ionic liquid, ratio of IL to gasoline, number of extraction steps, contact time (shaking time), and temperature in some instances, may significantly influence the extractive desulfurization efficiency of gasoline and diesel fuels with ILs (Wang et al. 2007; Mochizuki and Sugawara 2008; Kedra-Krolik et al. 2011). However, the influence of these factors has not been studied in detail. Experimental designs, as multivariate optimization techniques, have been widely used in various branches of chemistry such as synthesis (Zolfigol et al. 2014), chemical and biomedical analysis (Castro Sousa et al. 2008), preconcentration (Escudero et al. 2010), extraction (Chang et al. 2011), and other situations (Anunziata et al. 2008), because they are relatively fast, highly economical and effective, and allow several variables to be optimized simultaneously. This approach is applied to reduce the large amount of data so it can be easily interpreted to examine the main and interaction effects of experimental conditions on the efficiency of methods, and to obtain an estimate of the real functional relationship (response function) between the response of the system and significant factors (Morgan 1991).

In the present investigation, we attempt to optimize the extractive desulfurization of a model gasoline composed of seven sulfur compounds including alkyl thiols and aromatic compounds like thiophene (TP), 2-methylthiophene (2-MT), 3-methylthiophene (3-MT), and benzothiophene (BT) with respect to the above-mentioned parameters using experimental design. The optimized extraction conditions will be implemented for deep desulfurization of real gasoline samples following the adsorption process performed by means of activated Raney nickel as the adsorbent in acetonitrile solvent.

\section{Experimental}

\subsection{Materials}

All sulfur compounds including 1-propanethiol, 1-butanethiol, 1-pentanethiol, TP, 2-MT, 3-MT, BT, and other chemicals with the highest purity available from Merck (Darmstadt, Germany) were used without further purification. $N$-hexane, used as a solvent for sulfur compounds, was of analytical reagent grade from Acros (USA). The 1-butyl-3methylimidazolium tetrachloroaluminate ([BMIM] $\left[\mathrm{AlCl}_{4}\right]$, purity $>95 \%$, water content $=0.3 \%$ ) and 1-octyl-3methylimidazolium tetrafluoroborate ([OMIM] $\left[\mathrm{BF}_{4}\right]$, purity $>97 \%$, water content $=0.08 \%$ ) were purchased from Fluka and used as received. These ILs were used as extractants in liquid-liquid extraction for removal of sulfur compounds from model gasoline. 
The stock solution of the sulfur compounds in $n$-hexane was prepared as a model gasoline. The solution was prepared by dissolving 1-propanethiol, 1-butanthiol, 1-pentanthiol, TP, 2-MT, 3-MT, and BT in $n$-hexane. The total sulfur content of the stock solution, as measured in duplicate by X-ray fluorescence (XRF) spectrometer [according to ASTMD-2622 (1998)], was found to be $520 \mathrm{ppm}$. The stock solution used for investigating the extraction efficiency of $[\mathrm{BMIM}]\left[\mathrm{AlCl}_{4}\right]$ at the optimized conditions was also prepared from the above-mentioned compounds, and their concentrations were determined by a gas chromatograph and a sulfur chemiluminescence detector (GCSCD) (Table 4). The stock solutions were stored in a refrigerator at $5{ }^{\circ} \mathrm{C}$, and used as model of gasoline samples for extractive desulfurization experiments with ILs, as well as adsorptive desulfurization and adsorptive desulfurization (ADS) + IL tests. Real samples were collected from various sources of imported and locally produced gasoline.

\subsection{Apparatus and software}

All the desulfurization experiments were conducted in a 40-mL three-necked jacketed glass reactor equipped with a stirrer, a condenser, and a thermometer. The reactor was connected to a thermostatic bath, the temperature of which was maintained within $1{ }^{\circ} \mathrm{C}$. Good contact between phases was guaranteed by vigorous stirring, establishing required stirring times to achieve an equilibrium state for each one of the studied systems. The total sulfur content of the model gasoline before and after each extraction was measured in duplicate using a wavelength-dispersive XRF spectrometer (Horiba model 2800) (according to ASTMD2622) and by the Raney nickel reduction method [according to UOP Laboratory test method (1992) pp 357-80]. The water content of the ILs was determined using a KarlFischer instrument according to ASTM D-1533.

The solubility of ILs in gasoline was determined by analyzing the ionic liquid-saturated gasoline using a highperformance liquid chromatography (HPLC) (Stepnowski et al. 2003) with a Waters model 510 HPLC pump, equipped with UV-Vis detector at $295 \mathrm{~nm}$ wavelength and a C18 column. The mobile phase was a mixture with a methanol to water volume ratio of 80:20 at a flow rate of $1 \mathrm{~mL} \mathrm{~min}^{-1}$. The concentrations of the thiophenic compounds in model and real gasoline samples were determined with a gas chromatograph, Varian model CP 3800, equipped with a SCD, and CP-Sil column (30 m $\times 0.32 \mathrm{~mm}$ i.d.), operated with He carrier gas. The temperature program was from 32 to $220{ }^{\circ} \mathrm{C}$ at a ramping rate of $5^{\circ} \mathrm{C} \mathrm{min}^{-1}$.

\subsection{The fractional factorial design test}

The experimental design optimization was performed using STATISTICA 6.0 software. The extractive desulfurization of the model gasoline was investigated by factorial design. For this purpose, we used five parameters including shaking time $\left(X_{1}, \min \right)$, temperature $\left(X_{2},{ }^{\circ} \mathrm{C}\right)$, number of extraction steps $\left(X_{3}\right)$, IL to gasoline volume ratio $\left(X_{4}\right)$, and the type of IL $\left(X_{5}\right)$, each variable at two levels. The $[\mathrm{BMIM}]\left[\mathrm{AlCl}_{4}\right]$ and $[\mathrm{OMIM}]\left[\mathrm{BF}_{4}\right]$ were used as the two IL levels. Imidazolium-based ILs are known to be efficient extractants in desulfurization, especially for removal of aromatic sulfur compounds (Jiang et al. 2008; Nie et al. 2007; Rogosic et al. 2014). Although a two-level full factorial design can provide sufficient information to evaluate the whole set of main effects as well as interaction effects, it will require $2^{5}$ possible combinations, i.e., 32 experiments for five variables. The main effects and the lower-order interactions, however, are usually the most significant terms. In this work, a $2^{5-1}$ fractional factorial design consisting of 16 factorial runs was performed to reduce the experimental efforts. This allowed all the experiments to proceed in parallel to avoid possible impact caused by different experimental blocks. The maximum and minimum levels of each factor were chosen according to preliminary experiments (Table 1 ). The experiments were randomly performed in order to obtain a random distribution of unknown systematic errors.

\subsection{Procedure}

The extraction was carried out in the glass reactor by adding the ionic liquid to the model gasoline. The resulting mixture was stirred vigorously at $50{ }^{\circ} \mathrm{C}$ (or other specified temperatures). After a specified time, the upper phase (model gasoline) was carefully separated from the IL phase with a syringe for analysis. The total sulfur of the model gasoline was determined before and after each extraction by two methods: XRF (ASTM-D2622) and Raney nickel method (UOP 357-80) for samples with total sulfur $>100$ and $<100$ ppm, respectively.

The adsorption desulfurization experiments for real gasoline samples were performed in the same reactor described in Sect. 2.2, using a mixture of activated Raney nickel adsorbent and acetonitrile as mentioned above at $50{ }^{\circ} \mathrm{C}$ for $1 \mathrm{~h}$. Activated Raney nickel was prepared by putting $0.60 \pm 0.01 \mathrm{~g}$ of nickel-aluminum alloy in a $100-\mathrm{mL}$ beaker and adding $10 \mathrm{~mL}$ of $2.5 \mathrm{~m}$ sodium hydroxide. The beaker was swirled gently in a fume hood until the vigorous evolution of hydrogen ceased. Any solids 
Table 1 The value of high $(+)$ and low $(-)$ of the factors in $2^{5-1}$ fractional factorial design

\begin{tabular}{llll}
\hline Factors & Symbols & Levels & High $(+)$ \\
\cline { 4 - 4 } & & Low $(-)$ & 60 \\
\hline Shaking time, min & $X_{1}$ & 15 & 50 \\
Extraction temperature, ${ }^{\circ} \mathrm{C}$ & $X_{2}$ & 40 & 3 \\
Number of extraction steps $(n)$ & $X_{3}$ & 1 & $1 / 1$ \\
IL/gasoline volume ratio, v/v & $X_{4}$ & $1 / 5$ & {$[\mathrm{OMIM}]\left[\mathrm{BF}_{4}\right]$} \\
Type of IL & $X_{5}$ & {$\left[{\mathrm{BMIM}]\left[\mathrm{AlCl}_{4}\right]}\right.$}
\end{tabular}

remaining on the sides of the beaker were washed down with a minimum of water. The reaction was allowed to continue overnight in a covered vessel (such as a large desiccator minus desiccant). Then, the activated Raney nickel was stored in the beaker in the excess sodium hydroxide, in the covered vessel until ready for use. The beaker may be stored in the desiccator for a week.

Treatment of nickel-aluminum alloy with sodium hydroxide solution is one of the typical techniques for preparing activated Raney nickel. In this reaction, aluminum is oxidized to aluminate and hydrogen is evolved vigorously. This catalyst can adsorb a great amount of hydrogen through Van der Waals forces. Two reaction paths are known for the desulfurization process (Miran Beigi et al. 1999):

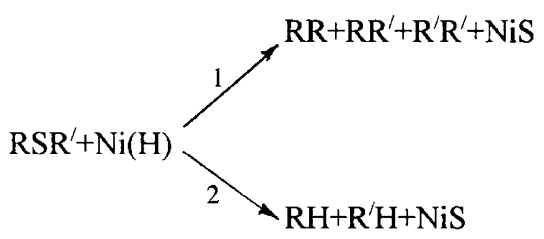

At high temperature and when the catalyst has been stored for a long period of time, the reaction will proceed through path 1. Apparently, the adsorbed hydrogen decreases at a temperature higher than $100{ }^{\circ} \mathrm{C}$. At low temperature and for freshly prepared catalyst, path 2 is preferred.

Activated Raney nickel and $10 \mathrm{~mL}$ of acetonitrile were added to $10 \mathrm{~mL}$ of a real gasoline sample. The mixture was stirred for $1 \mathrm{~h}$ and then the gasoline phase was separated and subjected to extraction by the IL ([BMIM] $\left[\mathrm{AlCl}_{4}\right]$ ), with a IL/gasoline volume ratio of $1: 1$, at temperature of $50{ }^{\circ} \mathrm{C}$ and contact time of $1 \mathrm{~h}$.

\section{Results and discussion}

\subsection{Optimization of the extraction method}

The optimization of experimental variables in the extraction of sulfur compounds from gasoline with ILs was carried out using a two-level $2^{5-1}$ fractional factorial design (i.e., 16 factorial runs). The five variables considered as factors were shaking time (min), temperature of the reactor $\left({ }^{\circ} \mathrm{C}\right)$, number of extraction steps $(n)$, IL to gasoline volume ratio $(\mathrm{v} / \mathrm{v})$, and the type of IL. Table 1 presents the variables and their real values at the high $(+)$ and low (-) levels set in the design. The experimental design matrix in which the effects of the five variables on sulfur removal were investigated, together with the total sulfur concentration and desulfurization efficiency is presented in Table 2. The runs were randomized for statistical purposes.

The significance of the effects of five variables was checked by analysis of the variance (ANOVA) (see Table 3) and by the Pareto chart in Fig. 1. It can be seen that two factors, namely number of extraction steps $\left(X_{3}\right)$ and IL/gasoline volume ratio $\left(X_{4}\right)$, were statistically significant with the latter variable $\left(X_{4}\right)$ being the most effective. The other factors, i.e., extraction temperature $\left(X_{2}\right)$, extraction time $\left(X_{1}\right)$, and type of IL $\left(X_{5}\right)$, were not significant in the ranges studied at the $95 \%$ confidence level. Also, none of the interactions were significant. Although not significant, extraction time exhibited a positive effect. Bearing this in mind, we selected the high level of this factor for further studies. The same is true for the effect of $X_{2}$ factor (reactor temperature). In this case, we used the high level of this factor, because the viscosity of ILs was reduced at higher temperatures which were expected to have a positive effect on the extraction efficiency, although as reported by Wang et al. (2007), the effect of temperature on the desulfurization with ILs is very limited. Also, the type of IL (factor $X_{5}$ ) was not significant and showed the least effect estimate. The interaction of this factor with all the other factors was also insignificant, but due to its negative interaction effects with the other factors and considering that all the other single factors had positive effects (especially the effects of $X_{3}$, number of extraction steps, and $X_{4}$, IL/gasoline volume ratio were positive and highly significant), we decided to use the lower level of $X_{5}$ ([BMIM] $\left.\left[\mathrm{AlCl}_{4}\right]\right)$ as IL.

On the other hand, solubility of the ILs should also be considered as an important factor in assessing their applicability as extractants. Noticeable solubility of imidazolium-based IL in gasoline may contaminate the fuel and lead to $\mathrm{NO}_{\mathrm{x}}$ pollution (Jiang et al. 2008). The solubility of the 
Table 2 The design matrix and analysis results from $2^{5-1}$ fractional factorial test. The total sulfur concentration in the model gasoline sample before performing the runs was $520 \mathrm{ppm}$

\begin{tabular}{|c|c|c|c|c|c|c|c|}
\hline \multirow[t]{2}{*}{ Standard run ${ }^{\mathrm{a}}$} & \multicolumn{5}{|c|}{ Factors } & \multirow[t]{2}{*}{ Total sulfur, after the runs, ppm } & \multirow[t]{2}{*}{ Desulfurization efficiency, $\%$} \\
\hline & $X_{1}$ & $X_{2}$ & $X_{3}$ & $X_{4}$ & $X_{5}$ & & \\
\hline $1(11)$ & - & - & - & - & - & 388 & 25.4 \\
\hline $2(13)$ & + & - & - & - & + & 323 & 37.9 \\
\hline $3(9)$ & - & + & - & - & + & 337 & 35.2 \\
\hline $4(15)$ & + & + & - & - & - & 320 & 38.4 \\
\hline $5(4)$ & - & - & + & - & + & 228 & 56.1 \\
\hline $6(12)$ & + & - & + & - & - & 267 & 48.6 \\
\hline $7(10)$ & - & + & + & - & - & 210 & 59.6 \\
\hline 8 (3) & + & + & + & - & + & 234 & 55.0 \\
\hline $9(5)$ & - & - & - & + & + & 207 & 60.2 \\
\hline $10(2)$ & + & - & - & + & - & 181 & 65.2 \\
\hline $11(16)$ & - & + & - & + & - & 309 & 40.6 \\
\hline $12(6)$ & + & + & - & + & + & 217 & 58.3 \\
\hline $13(1)$ & - & - & + & + & - & 143 & 72.5 \\
\hline $14(7)$ & + & - & + & + & + & 141 & 72.9 \\
\hline $15(14)$ & - & + & + & + & + & 144 & 72.3 \\
\hline $16(8)$ & + & + & + & + & - & 25 & 95.2 \\
\hline
\end{tabular}

${ }^{a}$ Values in parentheses indicate the randomized order in which the tests were run

Table 3 Results of ANOVA from the $2^{5-1}$ fractional factorial test for desulfurization of model gasoline

\begin{tabular}{llllll}
\hline Source & Sum of squares & Degrees of freedom & Mean squares & $F$ ratio & $p$ value \\
\hline$X_{1}$ & 153.76 & 1 & 153.76 & 64.000 & 0.07917 \\
$X_{2}$ & 15.602 & 1 & 15.602 & 6.4943 & 0.23806 \\
$X_{\mathbf{3}}^{*}$ & $\mathbf{1 8 2 7 . 6}$ & $\mathbf{1}$ & $\mathbf{1 8 2 7 . 6}$ & $\mathbf{7 6 0 . 6 9}$ & $\mathbf{0 . 0 2 3 0 7}$ \\
$\boldsymbol{X}_{\mathbf{4}}^{*}$ & $\mathbf{2 0 4 7 . 5}$ & $\mathbf{1}$ & $\mathbf{2 0 4 7 . 5}$ & $\mathbf{8 5 2 . 2 6}$ & $\mathbf{0 . 0 2 1 8 0}$ \\
$X_{5}$ & 0.3601 & 1 & 0.3601 & 0.1498 & 0.76488 \\
$X_{1} X_{2}$ & 51.840 & 1 & 51.840 & 21.578 & 0.13499 \\
$X_{1} X_{3}$ & 46.240 & 1 & 46.240 & 19.247 & 0.14267 \\
$X_{1} X_{4}$ & 112.36 & 1 & 112.36 & 46.768 & 0.09244 \\
$X_{1} X_{5}$ & 150.06 & 1 & 150.06 & 62.461 & 0.08013 \\
$X_{2} X_{3}$ & 145.20 & 1 & 145.20 & 60.438 & 0.08144 \\
$X_{2} X_{4}$ & 37.823 & 1 & 37.823 & 15.743 & 0.15718 \\
$X_{2} X_{5}$ & 50.410 & 1 & 50.410 & 20.982 & 0.13683 \\
$X_{3} X_{5}$ & 108.16 & 1 & 108.16 & 45.020 & 0.09419 \\
$X_{4} X_{5}$ & 30.250 & 1 & 30.250 & 12.5911 & 0.17489 \\
Error & 2.4020 & 1 & 2.4200 & & \\
Total & 4779.6 & 15 & & & \\
\hline
\end{tabular}

* Significant factors at $p<0.05$

Number of extraction steps $\left(X_{3}\right)$ and IL/gasoline volume ratio $\left(X_{4}\right)$ are statistically significant with the latter variable being the most effective
ILs in gasoline was examined by analysis of the ILsaturated gasoline samples with HPLC. No IL peak was found for $[\mathrm{BMIM}]\left[\mathrm{AlCl}_{4}\right]$, indicating its negligible solubility in gasoline; however $[\mathrm{OMIM}]\left[\mathrm{BF}_{4}\right]$ showed some solubility. Higher solubility of $[\mathrm{OMIM}]\left[\mathrm{BF}_{4}\right]$ versus $[\mathrm{BMIM}]\left[\mathrm{AlCl}_{4}\right]$ may be related to the increased lipophilicity of its imidazolium moiety as the alkyl substituents in the ILs increase from butyl to octyl, although the effect of the anionic moiety should not be ignored.

The effect of the two significant variables $\left(X_{3}\right.$ and $\left.X_{4}\right)$ was further investigated by taking several IL to gasoline volume ratios $(1 / 5,1 / 2$ and 1/1) and number of extraction 


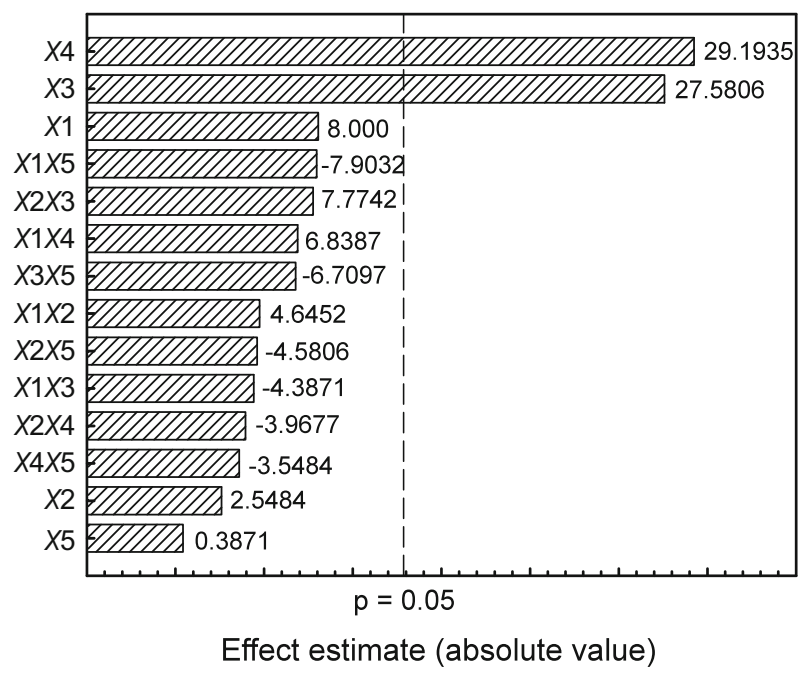

Fig. 1 Pareto chart of the standardized effects obtained for the factorial design optimization of the variables $X_{1}$ (shaking time), $X_{2}$ (reaction temperature), $X_{3}$ (number of extraction steps), $X_{4}$ (IL/gasoline volume ratio), $X_{5}$ (type of IL), and their interactions

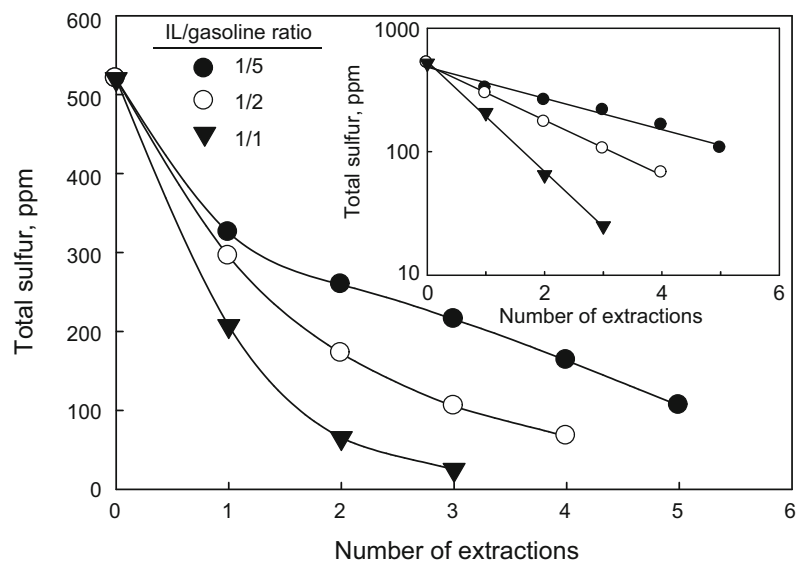

Fig. 2 Effect of number of extraction steps and IL to model gasoline volume ratio on desulfurization efficiency at $50{ }^{\circ} \mathrm{C}$, using $[\mathrm{BMIM}]\left[\mathrm{AlCl}_{4}\right]$ and extraction time of $1 \mathrm{~h}$. The inset figure shows the logarithm of sulfur concentration in gasoline versus the number of extraction steps

steps $(1,2,3,4$, and 5). The results, shown in Fig. 2, clearly indicated the strong dependence of desulfurization efficiency on both of these variables. As expected, higher efficiency could be achieved at higher IL/gasoline ratio and/or larger number of extraction steps. The logarithmic plot (log of sulfur concentration in gasoline versus the number of extraction steps), shown as inset in Fig. 2, indicated that the extraction was controlled by a constant distribution coefficient according to Nernst's law. It can be seen that in this case, the degree of desulfurization increased proportionally with the increase of IL to gasoline ratio. The effect of shaking time beyond the high level used in the design was investigated up to 6 at $1 \mathrm{~h}$ intervals and at different IL/gasoline ratios. No significant improvement was observed at extraction time $>1 \mathrm{~h}$. Based on the above results, $[\mathrm{BMIM}]\left[\mathrm{AlCl}_{4}\right]$ was used at $50{ }^{\circ} \mathrm{C}$ with $\mathrm{IL} /$ gasoline volume ratio of $1: 1$ and extraction time of $1 \mathrm{~h}$ for the following studies.

\subsection{Extraction of thiophenic sulfur compounds from model gasoline}

The results of extraction of aromatic sulfur compounds from the model gasoline with [BMIM] $\left[\mathrm{AlCl}_{4}\right]$, determined using GC-SCD, are presented in Table 4. The results indicated that the extraction efficiency was in the following order: $\mathrm{BT}>\mathrm{TP}>3$-MT $>2$-MT. This behavior can be related to the $\pi-\pi$ interaction between aromatic structures of sulfur compounds and the imidazolium ring of the IL (Krolikowski et al. 2013). BT, with its extended delocalized $\pi$ system, had a strong interaction with [BMIM] $\left[\mathrm{AlCl}_{4}\right]$ IL compared to TP and its alkyl substituted derivatives, therefore it was more easily extracted, with an efficiency of $96 \%$ (Table 4). The presence of methyl substituent in 2-MT and 3-MT significantly lowered their extraction efficiency with respect to TP, possibly due to the steric hindrance effect (Nie et al. 2008).

\subsection{Extraction of sulfur compounds from real gasoline samples}

Table 5 gives the total sulfur and different thiophenic compound concentrations in several real gasoline samples before and after extraction with $[\mathrm{BMIM}]\left[\mathrm{AlCl}_{4}\right]$. The samples were collected from various sources of imported and locally produced gasoline. The entry 1 shows a sample with a very high total sulfur content of $1400 \mathrm{ppm}$. While the total sulfur content of this sample decreased to 713 and $430 \mathrm{ppm}$ after one and four extraction cycles, respectively, the concentration of BT decreased to $<1 \mathrm{ppm}$ after the first step and those of TP, 2-MT, and 3-MT reached the same value after 4 steps. These results clearly indicated that while [BMIM] $\left[\mathrm{AlCl}_{4}\right]$ exhibited a high trend to extract some aromatic constituents such as thiophenic compounds, its ability to extract many other sulfur compounds was low, this is why the total sulfur content was still high (430 ppm) even after four extraction cycles. It is known that the aromatic sulfur compounds, such as thiophenic compounds, in which a conjugation occurs between the lonepair on $\mathrm{S}$ atom and the $\pi$-electrons on the aromatic ring, can preferably insert into the dynamic molecular structure of the ILs (Song 2003). On the other hand, when there is no such conjugation, as in the case of many sulfides, disulfides, and thiols, the compounds exhibit lower trends for 
Table 4 Extraction efficiency of thiophenic sulfur compounds from the model gasoline with [BMIM][AlCl $\left.\mathrm{B}_{4}\right]$ as determined by GC-SCD

\begin{tabular}{lllll}
\hline Compound & Initial content, ppm & After extraction, ppm & S content after extraction, ppm & Efficiency, \% \\
\hline TP & 634 & 173 & 65.8 & 72.7 \\
2-MT & 224 & 100 & 32.6 & 55.4 \\
3-MT & 240 & 101 & 32.9 & 58.0 \\
BT & 280 & 11 & 2.62 & 96.1
\end{tabular}

Conditions: temperature $50{ }^{\circ} \mathrm{C}$, extraction time $1 \mathrm{~h}$, number of extraction steps 3

Table 5 Concentration of total sulfur and thiophenic compounds $(\mathrm{ppm})$ in real gasoline samples before (B) and after (A) extraction with $[\mathrm{BMIM}]\left[\mathrm{AlCl}_{4}\right]$

\begin{tabular}{|c|c|c|c|c|c|c|c|c|c|c|}
\hline \multirow[t]{2}{*}{ Gasoline sample } & \multicolumn{2}{|c|}{ Total sulfur } & \multicolumn{2}{|l|}{$\mathrm{TP}$} & \multicolumn{2}{|c|}{ 2-MT } & \multicolumn{2}{|c|}{ 3-MT } & \multicolumn{2}{|l|}{ BT } \\
\hline & B & A & B & A & B & A & B & A & B & A \\
\hline \multirow[t]{2}{*}{1} & 1400 & 713 & 42 & 5 & 140 & 9 & 45 & 6 & 105 & $<1$ \\
\hline & & 430 (4) & & $<1(4)$ & & $<1(4)$ & & $<1(4)$ & & \\
\hline \multirow[t]{2}{*}{2} & 124 & 71 & 20 & 9 & 21 & 12 & 26 & 14 & 29 & 10 \\
\hline & & $41(2)$ & & $3(2)$ & & $6(2)$ & & $7(2)$ & & $4(2)$ \\
\hline 3 & 294 & 129 & 15 & 2 & 22 & 5 & 15 & 4 & 17 & 3 \\
\hline 4 & 142 & 60 & 32 & 11 & 27 & 13 & 27 & 13 & 15 & 5 \\
\hline 5 & 100 & 55 & 22 & 8 & 22 & 12 & 27 & 14 & 28 & 9 \\
\hline 6 & 154 & 40 & 19 & 2 & 20 & 3 & 28 & 4 & 32 & $<1$ \\
\hline 7 & 118 & 91 & 19 & 7 & 18 & 10 & 19 & 6 & 23 & $<1$ \\
\hline
\end{tabular}

Conditions: temperature $50{ }^{\circ} \mathrm{C}$; extraction time $1 \mathrm{~h}$; IL to gasoline volume ratio 1

The values in parentheses indicate the number of extraction steps

extraction with ILs. A close inspection of Table 5 reveals that for most samples, the IL reduced the total sulfur to about half of their initial values (entries 1-5), but for samples 6 and 7, the remaining concentration was, respectively, $26 \%$ and $77 \%$, indicating the fact that the extraction efficiency depended on the nature of the samples, which can be explained by the variety of compounds present in the gasoline samples.

\subsection{Desulfurization of real gasoline samples by IL and ADS + IL extraction}

The above results, lead to the conclusion that although the IL ([BMIM] $\left[\mathrm{AlCl}_{4}\right]$ ) is highly effective for the extraction of aromatic sulfur compounds and can lower their concentration to very low levels, it does not provide adequate efficiency for decreasing total sulfur concentration to acceptable levels for many gasoline samples. Therefore, in continuation of our research, we tried a combination of ADS and IL in a successive manner. At first, in the adsorption process, the acetonitrile solvent was examined alone for desulfurization. Acetonitrile solvent $(10 \mathrm{~mL})$ was added to $10 \mathrm{~mL}$ of real gasoline sample 1 . The mixture was stirred at $50{ }^{\circ} \mathrm{C}$ for $1 \mathrm{~h}$ and then the gasoline phase was separated. After this step, the total sulfur concentration in gasoline sample 1 decreased from 1400 to $720 \mathrm{ppm}$. In the next experiment, $10 \mathrm{~mL}$ of acetonitrile solvent containing $0.6 \mathrm{~g}$ of activated Raney nickel was added to $10 \mathrm{~mL}$ of gasoline sample 1 and the mixture was stirred at the same conditions. The total sulfur concentration in this sample decreased from 1400 to $267 \mathrm{ppm}$. This result clearly indicated the ability of activated Raney nickel in extracting a considerable amount of sulfur compounds. Moreover, other experiments were carried out by ionic liquid and activated Raney nickel. A $10 \mathrm{~mL}$ of $[\mathrm{BMIM}]\left[\mathrm{AlCl}_{4}\right]$ ionic liquid containing $0.6 \mathrm{~g}$ of activated Raney nickel was added to $10 \mathrm{~mL}$ of gasoline sample 1 and the mixture was stirred at $50{ }^{\circ} \mathrm{C}$ for $1 \mathrm{~h}$. The total sulfur concentration reduced from 1400 to $520 \mathrm{ppm}$. This result also indicated that activated Raney nickel can be regarded as an efficient desulfurization strategy. Table 6 shows the results obtained from using IL extraction, acetonitrile solvent, acetonitrile solvent containing activated Raney nickel, IL containing activated Raney nickel, and acetonitrile solvent containing activated Raney nickel + IL (ADS + IL).

The ADS + extraction experiments were performed according to the procedure described in Sect. 2.4. The concentrations of total sulfur before and after the ADS + IL processes are presented in Table 7. Comparing the results of IL extraction alone and ADS + IL extraction 
Table 6 Concentration of total sulfur (ppm) in real gasoline sample 1 before (B) and after (A) desulfurization

\begin{tabular}{|c|c|c|c|c|c|c|}
\hline \multirow{2}{*}{$\begin{array}{l}\text { Gasoline } \\
\text { sample }\end{array}$} & \multirow{2}{*}{$\begin{array}{l}\text { Total } \\
\text { sulfur, ppm } \\
\text { (B) }\end{array}$} & \multicolumn{5}{|c|}{ Total sulfur after treatment, ppm } \\
\hline & & (A) IL & $\begin{array}{l}\text { (A) Acetonitrile } \\
\text { solvent }\end{array}$ & $\begin{array}{l}\text { (A) Acetonitrile } \\
\text { solvent }+ \text { activated Raney } \\
\text { nickel }\end{array}$ & $\begin{array}{l}\text { (A) IL + activated } \\
\text { Raney nickel }\end{array}$ & $\begin{array}{l}\text { (A) Activated Raney } \\
\text { nickel + acetonitrile } \\
\text { solvent + IL (ADS + IL) }\end{array}$ \\
\hline 1 & 1400 & 713 & 720 & 267 & 520 & 154 \\
\hline
\end{tabular}

Conditions: temperature $50{ }^{\circ} \mathrm{C}$; reaction time $1 \mathrm{~h}$

Table 7 Concentration of total sulfur (ppm) in real gasoline samples before (B) and after (A) ADS + IL treatment

\begin{tabular}{lrrrl}
\hline Gasoline sample & Total sulfur (B) & \multicolumn{2}{c}{ Total sulfur after treatment (A), ppm } & Efficiency of ADS + IL \\
\cline { 3 - 4 } & & IL & ADS + IL & 89.0 \\
\hline 1 & 1400 & 713 & 154 & 71.0 \\
2 & 124 & 71 & 36 & 87.8 \\
3 & 294 & 129 & 36 & 75.4 \\
4 & 142 & 60 & 35 & 84.0 \\
5 & 100 & 55 & 16 & \\
\hline
\end{tabular}

Conditions: temperature $50{ }^{\circ} \mathrm{C}$; reaction time $1 \mathrm{~h}$; ADS-phase $(0.60 \mathrm{~g}$ of activated Raney nickel in $10 \mathrm{~mL}$ acetonitrile solvent): gasoline volume ratio 1:1 in Table 7 shows that the ADS process is more efficient for removing total sulfur concentration in most of the samples. For example, it can be observed from these tables that the total sulfur concentration in sample 1 has reduced from 1400 to $154 \mathrm{ppm}$ by the ADS + IL and $713 \mathrm{ppm}$ by the IL extraction processes (efficiency of 89.0 and $49.1 \%$, respectively). Similarly, the sulfur removal efficiency of samples 2 and 3 by the ADS + IL processes is 71.0 and 87.8 , respectively, compared to the corresponding values of 42.7 and 56.1, respectively, for the IL extraction. These results indicate that IL extraction can be used as a complementary process to the ADS. Therefore, ADS combined with IL extraction, which operates near ambient conditions and provides high efficiency and selectivity, can be regarded as a promising energy efficient desulfurization strategy for the production of low-sulfur gasoline.

\subsection{Extraction of other aromatic compounds (dearomatization) from real gasoline samples by IL}

$[\mathrm{BMIM}]\left[\mathrm{AlCl}_{4}\right]$ was used to extract other aromatic compounds from gasoline (Farzin Nejad and Karimi 2011). The dearomatization experiments were carried out with an ionic liquid to gasoline volume ratio of $1: 1$ at $50{ }^{\circ} \mathrm{C}$ for $1 \mathrm{~h}$. The aromatic hydrocarbons removal selectivity exhibited the following order: benzene $>$ toluene $>$ xylene $>$ ethylbenzene.

\subsection{Regeneration of ILs}

$[\mathrm{OMIM}]\left[\mathrm{BF}_{4}\right]$ was regenerated by direct distillation under a nitrogen atmosphere at $170{ }^{\circ} \mathrm{C}$ for $3 \mathrm{~h}$. After the regeneration was completed, the ionic liquid was mixed with fresh gasoline sample 1 and the second extraction cycle was performed. The results showed that the desulfurization efficiency was $87 \%$ in the first regeneration cycle and $72 \%$ in the second cycle.

In all the cases of this work, when [BMIM] $\left[\mathrm{AlCl}_{4}\right]$ contacted with the gasoline samples, it turned black immediately. This phenomenon indicated the decomposition of [BMIM] $\left[\mathrm{AlCl}_{4}\right]$ due to the presence of Lewis acid IL. A potential disadvantage of this particular IL is its sensitivity toward water and possible difficulty associated with its regeneration. [BMIM] $\left[\mathrm{AlCl}_{4}\right]$ was regenerated through contacting it with an organic medium such as toluene; however, this method has not proven to be completely effective in the case of [BMIM] $\left[\mathrm{AlCl}_{4}\right]$.

\section{Conclusions}

The optimization of experimental variables in the extraction of sulfur compounds from gasoline by ILs was carried out using a two-level fractional factorial design. It was found that the number of extraction steps and IL/gasoline volume ratio was statistically significant with the latter variable being the most effective. The type of IL was not significant and showed the least effect estimate. At the optimized conditions, the extraction process was applied to the desulfurization of several real gasoline samples. The results indicated that the ionic liquid provides a high tendency to extract some aromatic constituents such as thiophenic compounds in both model and real gasoline samples. Due to the inability of the ionic liquid to lower 
total sulfur compounds in real gasoline samples to a desirable level, an IL extraction was applied as a complementary process to the ADS, which was performed by activated Raney nickel adsorbent and acetonitrile solvent. The sulfur content of the samples after treatment with the combined desulfurization scheme presented a considerable reduction and reached to $>71 \%$ for all of the samples. The results indicated that the ADS + IL extraction provides high efficiency and selectivity and can be regarded as a promising energy efficient desulfurization strategy for the production of low-sulfur gasoline. It is expected that the desulfurization efficiency can be further improved by optimizing the ADS operating parameters, such as reaction temperature, reaction time, and the amount and proportion of reactants, to obtain ultra-low-sulfur gasoline.

Acknowledgments The authors thank National Iranian Oil Refining \& Distribution Company (NIORDC) and Research \& Development (R\&D) center of this company for their financial support during the completion of this work.

Open Access This article is distributed under the terms of the Creative Commons Attribution License which permits any use, distribution, and reproduction in any medium, provided the original author(s) and the source are credited.

\section{References}

Annual book of ASTM standards. ASTM D-2622: sulfur in petroleum products (X-ray spectrographic method). Philadelphia: PA; 1998.

Anunziata OA, Cussa J. Applying response surface design to the optimization of methane activation with ethane over Zn-H-ZSM11 zeolite. Chem Eng J. 2008;138:510-6.

Boshagh F, Mokhtarani B, Mortaheb HR. Effect of electrokinetics on biodesulfurization of the model oil by Rhodococcus erythropolis PTCC1767 and Bacillus subtilis DSMZ 3256. J Hazard Mater. 2014;280:781-7.

Sousa JKC, de Sousa Dantas AN, Marques ALB, et al. Experimental design applied to the development of a copper direct determination method in gasoline samples by graphite furnace atomic absorption spectrometry. Fuel Process Technol. 2008;89:1180-5.

Chang SH, Teng TT, Ismail N. Screening of factors influencing $\mathrm{Cu}$ (II) extraction by soybean oil-based organic solvents using fractional factorial design. J Environ Manage. 2011;92:2580-5.

Domanska U, Walczak K, Królikowski M. Extraction desulfurization process of fuels with ionic liquids. J Chem Thermodyn. 2014;77:40-5.

Escudero LA, Cerutti S, Olsina RA, et al. Factorial design optimization of experimental variables in the on-line separation/preconcentration of copper in water samples using solid phase extraction and ICP-OES determination. J Hazard Mater. 2010;183:218-23.

Farzin Nejad N, Karimi EA. A new approach to dearomatization of gasoline by ionic liquid and liquid-liquid extraction. Pet Sci Technol. 2011;29:2372-6.

Fernandez M, Ramirez M, Gomez JM, et al. Biogas biodesulfurization in an anoxic biotrickling filter packed with open-pore polyurethane foam. J Hazard Mater. 2014;264:529-35.

Hansmeier AR, Meindersma GW, de Haan AB. Desulfurization and denitrogenation of gasoline and diesel fuels by means of ionic liquids. Green Chem. 2011;13:1907-13.
Jiang XC, Nie Y, Li CX, et al. Imidazolium-based alkylphosphate ionic liquids-a potential solvent for extractive desulfurization of fuel. Fuel. 2008;87:79-84.

Kedra-Krolik K, Fabrice M, Jaubert JN. Extraction of thiophene or pyridine from n-heptane using ionic liquids. Gasoline and diesel desulfurization. Ind Eng Chem Res. 2011;50:2296-306.

Krolikowski M, Walczak K, Domanska U. Solvent extraction of aromatic sulfur compounds from $n$-heptane using the 1-ethyl-3methylimidazolium tricyanomethanide ionic liquid. J Chem Thermodyn. 2013;65:168-73.

Li FT, Liu Y, Sun ZM, et al. Deep extractive desulfurization of gasoline with $\mathrm{xEt}_{3} \mathrm{NHCl}_{3} \cdot \mathrm{FeCl}_{3}$ ionic liquids. Energy Fuels. 2010;24:4285-9.

Ma C, Dai B, Liu P, et al. Deep oxidative desulfurization of model fuel using ozone generated by dielectric barrier discharge plasma combined with ionic liquid extraction. J Ind Eng Chem. 2014;20:2769-74.

Mansouri A, Khodadadi AA, Mortazavi YA. Ultra-deep adsorptive desulfurization of a model diesel fuel on regenerable $\mathrm{Ni}-\mathrm{Cu} / \gamma$ $\mathrm{Al}_{2} \mathrm{O}_{3}$ at low temperatures in absence of hydrogen. $\mathrm{J}$ Hazard Mater. 2014;271:120-30.

Miran Beigi AA, Teymouri M, Eslami M, et al. Determination of trace sulfur in organic compounds by activated Raney nickel desulfurization method with non-dispersive gas detection system. Analyst. 1999;124:767-70.

Mochizuki Y, Sugawara K. Removal of organic sulfur from hydrocarbon resources using ionic liquids. Energy Fuels. 2008;22:3303-7.

Mokhtar WNAW, Bakar WAWA, Ali R, et al. Deep desulfurization of model diesel by extraction with $\mathrm{N}, \mathrm{N}$-dimethylformamide: optimization by Box-Behnken design. J Taiwan Inst Chem Eng. 2014:45:1542-8.

Morgan ED. Chemometrics: experimental design. ACOL. London: Wiley; 1991.

Nie Y, Li CX, Meng H, et al. N, N-Dialkylimidazolium dialkylphosphate ionic liquids: their extractive performance for thiophene series compounds from fuel oils versus the length of alkyl group. Fuel Process Technol. 2008;89:978-83.

Nie Y, Li CX, Sun A, et al. Extractive desulfurization of gasoline using imidazolium-based phosphoric ionic liquids. Energy Fuels. 2006;20:2083-7.

Nie Y, Li CX, Wang ZH. Extractive desulfurization of fuel oil using alkylimidazole and its mixture with dialkylphosphate ionic liquids. Ind Eng Chem Res. 2007;46:5108-12.

Rogosic M, Sander A, Pantaler M. Application of 1-pentyl-3methylimidazolium bis (trifluoromethylsulfonyl) imide for desulfurization, denitrification and dearomatization of FCC gasoline. J Chem Thermodyn. 2014;76:1-15.

Sampanthar JT, Xiao H, Dou J, et al. A novel oxidative desulfurization process to remove refractory sulfur compounds from diesel fuel. Appl Catal B. 2006;63:85-93.

Sevignon M, Macaud M, Favre-Reguillon A, et al. Ultra-deep desulfurization of transportation fuels via charge-transfer complexes under ambient conditions. Green Chem. 2005;7:413-20.

Shi Y, Liu G, Wang L, et al. Efficient adsorptive removal of dibenzothiophene from model fuel over heteroatom-doped porous carbons by carbonization of an organic salt. Chem Eng J. 2015;259:771-8.

Song C. An overview of new approaches to deep desulfurization for ultra-clean gasoline, diesel fuel and jet fuel. Catal Today. 2003;86:211-63.

Stepnowski P, Muller A, Behrend P, et al. Reversed-phase liquid chromatographic method for the determination of selected room temperature ionic liquid cations. J Chromatogr A. 2003;993: $173-8$. 
UOP Laboratory Test Method. Trace sulfur in petroleum distillate by the nickel reduction method. Des Plaines: Universal Oil Products; 1992. p. 357-80.

Wang JL, Zhao DS, Zhou EP, et al. Desulfurization of gasoline by extraction with n-alkyl-pyridinium-based ionic liquids. J Fuel Chem Technol. 2007;35:293-6.

Zhang M, Zhu W, Xun S, et al. Deep oxidative desulfurization of dibenzothiophene with POM-based hybrid materials in ionic liquids. Chem Eng J. 2013;220:328-36.
Zolfigol MA, Khazaei A, Sarmasti N, et al. Programming of microwave-assisted synthesis of new isophthalate derivatives using $\mathrm{ZrOCl}_{2}$ as a catalyst under solvent-free condition by experimental design. J Mol Catal A: Chem. 2014;393:142-9. 